\title{
Microbial diversity and methanogenic activity of Antrim Shale formation waters from recently fractured wells
}

\author{
Cornelia Wuchter $^{1 *}$, Erin Banning ${ }^{1 \dagger}$, Tracy J. Mincer ${ }^{1}$, Nicholas J. Drenzek ${ }^{2 \dagger}$ and Marco J. L. Coolen ${ }^{1}$ \\ ${ }^{1}$ Marine Chemistry and Geochemistry Department, Woods Hole Oceanographic Institution, Woods Hole, MA, USA \\ ${ }^{2}$ Reservoir Geosciences Department, Schlumberger Doll Research, Cambridge, MA, USA
}

\section{Edited by: \\ Kartik Chandran, Columbia \\ University, USA}

Reviewed by:

John Stolz, Duquesne University, USA

Tim Magnuson, Idaho State

University, USA

\section{*Correspondence:}

Cornelia Wuchter, Marine Chemistry and Geochemistry Department,

Woods Hole Oceanographic

Institution, 360 Woods Hole Road,

Woods Hole, MA 02543, USA

e-mail: c_wuchter@hotmail.com

${ }^{\dagger}$ Present address:

Erin Banning, Algenol Biofuels Inc., Bonita Springs, USA

Nicholas J. Drenzek, Unconventional

Shale Oil and Gas Sector, Statoil

Research Center, Bergen, Norway
The Antrim Shale in the Michigan Basin is one of the most productive shale gas formations in the U.S., but optimal resource recovery strategies must rely on a thorough understanding of the complex biogeochemical, microbial, and physical interdependencies in this and similar systems. We used Illumina MiSeq $16 \mathrm{~S}$ rDNA sequencing to analyze the diversity and relative abundance of prokaryotic communities present in Antrim shale formation water of three closely spaced recently fractured gas-producing wells. In addition, the well waters were incubated with a suite of fermentative and methanogenic substrates in an effort to stimulate microbial methane generation. The three wells exhibited substantial differences in their community structure that may arise from their different drilling and fracturing histories. Bacterial sequences greatly outnumbered those of archaea and shared highest similarity to previously described cultures of mesophiles and moderate halophiles within the Firmicutes, Bacteroidetes, and $\delta$ - and $\varepsilon$-Proteobacteria. The majority of archaeal sequences shared highest sequence similarity to uncultured euryarchaeotal environmental clones. Some sequences closely related to cultured methylotrophic and hydrogenotrophic methanogens were also present in the initial well water. Incubation with methanol and trimethylamine stimulated methylotrophic methanogens and resulted in the largest increase in methane production in the formation waters, while fermentation triggered by the addition of yeast extract and formate indirectly stimulated hydrogenotrophic methanogens. The addition of sterile powdered shale as a complex natural substrate stimulated the rate of methane production without affecting total methane yields. Depletion of methane indicative of anaerobic methane oxidation (AMO) was observed over the course of incubation with some substrates. This process could constitute a substantial loss of methane in the shale formation.

\section{Keywords: Antrim gas shale, biogenic gas, formation water, fermenting bacteria, methanogens}

\section{INTRODUCTION}

Microbial gas formation through decomposition of sedimentary organic matter $(\mathrm{OM})$ comprises roughly $20 \%$ of the world's natural gas resources (Rice, 1992), and it is estimated that even more microbial gas is retained in the corresponding source rocks of unconventional biogenic gas shales (Milkov, 2011). In the U.S. unconventional gas resources account for nearly $10 \%$ of the total natural gas generation (Martini et al., 2003). The Michigan Basin, centered on the lower peninsula of Michigan in the U.S., is home of the Devonian ( $\sim 380$ Ma-old) Antrim Shale formation, one of the most productive gas shale formations in the U.S. The finely laminated Antrim Shale contains thermally immature OM with a total organic carbon (TOC) content of $0.5-24 \%$ (Shurr and Ridgley, 2002). In the central and eastern Michigan basin the Antrim shale contains thermogenic gas, created by pressure and thermal cracking of OM. Here, gas production rates in drilled wells are low and economically not successful (Martini et al., 2008). In contrast, shale gas production along the northern margin of the Michigan Basin is high and became a target area of rapid development starting with 100 wells in 1985 to over 12,000 gas-and water producing wells installed today (Martini et al., 2004; DEQ, 2012). Previous geochemical studies provided evidence for biologically mediated methane generation in the recent geological past along the northern margin of the Michigan Basin (Martini et al., 1996). Dilution of deep basin brines with meteoric waters and deep groundwater recharge during Pleistocene glaciations resulted in a steep salinity gradient in Antrim Shale pore waters with extremely diluted water along the margins to greater than $5 \mathrm{M} \mathrm{NaCl}$ at the center of the basin (McIntosh et al., 2002). The Antrim shale has been hydrologically isolated from surface water for at least 7000 years (Martini et al., 1998; McIntosh et al., 2002) and the formation water lacks abundant inorganic electron acceptors other than carbon dioxide, including sulfate and iron oxyhydroxides (Waldron et al., 2007). Such conditions are favorable for methanogens which often thrive in environments where carbon dioxide is the sole available electron acceptor (Whitman et al., 2006). Although the high salt concentrations in the Antrim formation water inhibit many microorganisms, halophilic organisms can thrive under a wide range of $\mathrm{NaCl}$ concentrations (Oren, 1999). A recent study on enrichment cultures from formation 
water of the methane-generating zone of the Antrim shale provided evidence of halophilic methanogenic communities growing at up to $2.5 \mathrm{M} \mathrm{NaCl}$ concentrations (Waldron et al., 2007), indicating that active methanogenesis is an ongoing process in the northern margins of the Antrim gas shale.

Although little is known of microbial communities in gas shale formations, similarly hydrocarbon-rich, anaerobic environments such as petroleum reservoirs and subsurface coal beds have been relatively well-studied (Magot et al., 2000; Strapoć et al., 2008, 2011). Similar to the Antrim Shale, carbon dioxide is the predominantly bioavailable electron-acceptor in coal bed formation water (Strąpoć et al., 2011). Several studies have demonstrated the presence of active methanogenic archaea in coal beds (Shumkov et al., 1999; Green et al., 2008; Harris et al., 2008; Orem et al., 2010) and some have reported enhanced methane production with increases in surface area (Green et al., 2008), addition of inorganic nutrients (Harris et al., 2008) and trace elements (Ünal et al., 2012). The conversion of refractory OM to methane involves primarily the fermentation of polymers and monomers to fatty acids, organic acids, alcohols, hydrogen, and carbon dioxide. Subsequently degradation follows via secondary fermenting bacteria, homoacetogenic bacteria and acetoclastic, methylotrophic and hydrogenotrophic methanogens (Schink, 2006).

Similarly to coal bed formations, gas shale formations have shown enhanced methane production with increased surface area (Curtis, 2002). Horizontal drilling and hydraulic fracturing have now become two key technologies in shale gas exploration (Arthur et al., 2008; Kerr, 2010). During the drilling operation large volumes of drilling mud are pumped into the formation to cool and lubricate the drilling bit. Drilling mud contains cellulose, barite, and lignosulfonates (Caenn et al., 2011, www. fracfocus.org), which could serve as carbon and sulfate sources for microorganisms. Hydraulic fracturing is a widely used technique to fracture gas shale by pumping fluids and sand into production wells at high pressure (Arthur et al., 2008), resulting in enhanced methane extraction. Biocides are added to the fracturing water to control bacterial growth (Arthur et al., 2008), although recent studies have shown that bacteria can survive this treatment (e.g., Struchtemeyer and Elshahed, 2012) and additives such as polyacrylamide and sugar-based polymers might even be utilized microbially (Arthur et al., 2008). Despite the widespread utilization of the drilling and hydraulic fracturing procedures not much is known about the impact on the microbial communities present in formation water.

Here, we phylogenetically characterized the prokaryotic community in formation waters of three recently fractured gasproducing wells (denoted A3-11, B1-12, and C1-12) from the western margin (Manistee county) of the Antrim Shale to identify possible key microbial players in methanogenic shale gas production. Incubation experiments with formation water were performed to stimulate methanogenic communities using a variety of substrates. Direct methanogenic substrates tested include small organic acids, methanol, and trimethylamine (TMA). Sterile powdered shale, yeast extract, propionate, and glucose were used to test the ability of bacteria to convert these compounds into methanogenic substrates. Phylogenetic surveys of the incubation experiments were performed to identify the microbial communities that were stimulated by the various substrate additives. Methanol, TMA, and yeast extract substrates were monitored for consumption.

\section{MATERIALS AND METHODS SAMPLING AND SAMPLING LOCATION}

The three investigated closely spaced $(<1 \mathrm{~km})$ gas-producing wells A3-11, B1-12, and C1-12 are located in the Antrim shale section of the western Michigan Basin (Manistee county) (Figure 1 and Supplementary Figure S1). All three wells were hydraulically fractured by a nitrogen foam method $\sim 5$ months prior to sampling of production water for this study. Unlike B1-12 and C1-12, A3-11 was originally drilled and brought into production more than 2 years before this study's sampling and was hydraulically fractured a total of three times, initially by different fracturing methods (Table 1). Formation water was collected at the wellhead in sterilized 1L pyrex screw cap bottles for chemical and molecular biological analyses as well as for incubation experiments. During sampling all air was removed from the collection bottles by filling them to overflowing as described previously (Huang, 2008). The anaerobic water samples were immediately placed on ice in the dark and shipped overnight to the WHOI laboratory. Well water sample bottles were transferred to an anaerobic glove box under a 95:5 $\mathrm{N}_{2}: \mathrm{H}_{2}$ atmosphere and inspected for accidental oxygen entrainment by adding well water subsamples to (clear and colorless) resazurin-containing media for color change. For DNA analyses biomass from 300-mL aliquots of native formation water from each well was collected on $0.2-\mu \mathrm{m}$ Sterivex filters and kept frozen at $-80^{\circ} \mathrm{C}$ until further analysis. Well water chemistry was measured with an ICP-MS system at the Analytical Chemical Testing Laboratory, Inc. (ACT, Mobile, AL).

\section{INCUBATION EXPERIMENTS}

The sampled anaerobic well water served as natural media for the incubation experiments. For the incubation experiments $45 \mathrm{~mL}$ of anaerobic well water was transferred to $140-\mathrm{mL}$ sterile glass serum bottles and supplemented with $500 \mu \mathrm{L}$ aliquots of sterilized anaerobic solutions of the appropriate substrate stock solutions. All steps involved in the set-up of the incubation experiment were performed in an anaerobic glove box (Coy Laboratory Products, Grass Lake, MI) under an atmosphere of at least 95\% nitrogen and up to $5 \%$ hydrogen gas. Substrates included acetate, formate, glucose, propionate, and trimethylamine (TMA) at a final concentration of $\sim 10 \mathrm{mM}$, yeast extract at a concentration of $\sim 0.5$ $\mathrm{g} / \mathrm{L}$, or a $0.44 \%(\mathrm{v} / \mathrm{v})$ final concentration of methanol. Powdered sterile shale was also tested as a substrate to gauge the potential of the rock's native bitumen as a growth substrate, with one gram added to the appropriate incubation bottles before the addition of well water. This shale material was retrieved from a $50 \mathrm{~m}$ core traversing the Antrim pay zone while drilling the C1-12 well. From an organic-rich section shale material was then pulverized via mortar and pestle in the lab and autoclaved dry for addition to subsequent microbial incubations.

Incubations were conducted in duplicate for each tested substrate and monitored for up to 250 days. Each bottle also received $1 \mathrm{~mL}$ of a $100 \mathrm{mM}$ sodium sulfide solution, $500 \mu \mathrm{L}$ of a vitamin solution, and $100 \mu \mathrm{L}$ of a one molar phosphate solution as 
additional nutrients (Whitman et al., 2006) to avoid limitation by these nutrients. Following all additions, the bottles were sealed with autoclaved butyl rubber stoppers that had been boiled for $2 \mathrm{~h}$ in a $2 \mathrm{M}$ sodium hydroxide solution to remove any traces of methane or organic contaminants. The bottles were removed from the glove box and their headspaces purged by flowing a pressurized 80:20 nitrogen:carbon dioxide mix through 0.2- $\mu \mathrm{m}$ filters and the stoppers and then over pressured to about $100 \mathrm{kPa}$, using a bench top gassing station. All bottles were incubated in the dark at room temperature $\left(25^{\circ} \mathrm{C}\right)$ without agitation.

A 2-mL gas-tight syringe with Luer ${ }^{\circledR}$ fitting (Valco Instruments Co. Inc., Houston, TX) was used to sample headspace gases from each incubation bottle every 1-3 weeks. For each time point, $250 \mu \mathrm{L}$ of headspace gas was withdrawn after $250 \mu \mathrm{L}$ of sterile 80:20 nitrogen:carbon dioxide mix was pushed into the bottle from the purged syringe to avoid progressive drops in gas pressure in the bottle headspaces. A similar volume replacement procedure was used for liquid samples of $1 \mathrm{~mL}$, withdrawn with

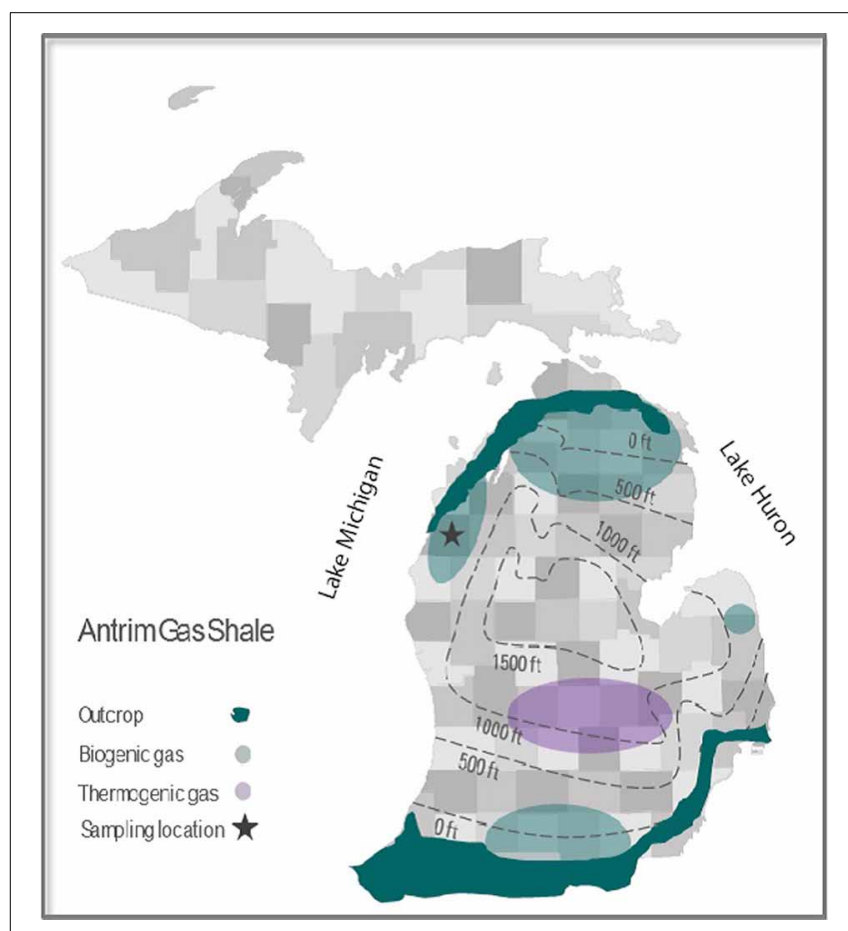

FIGURE 1 | County map of the Antrim gas shale formation with average depth contours, outcrops, and major biogenic and thermogenic production regions delineated. The location of the wells sampled for this study is also shown. sterile disposable 5-mL syringes purged with the nitrogen and carbon dioxide gas mix. Every liquid sample was divided between substrate $(500 \mu \mathrm{L}$ filtered through a $0.2-\mu \mathrm{m}$ filter and frozen at $\left.-20^{\circ} \mathrm{C}\right)$ and DNA $\left(500 \mu \mathrm{L}\right.$ immediately frozen at $-20^{\circ} \mathrm{C}$ for subsequent DNA extraction).

\section{Microbial gas measurements during incubations}

The concentrations of methane and hydrogen in gas samples retrieved from each incubation bottle were quantified against a five-point calibration dilution of a custom 1 vol\% $\mathrm{CH}_{4} / \mathrm{H}_{2}$ American Air Liquide standard mix on a HP 5890 Series II gas chromatograph (GC) equipped with a 2-m washed molecular sieve $13 \times 80 / 100$ column and onboard thermal-conductivity and flame-ionization detectors by direct injection. Total gas abundances were then calculated from liquid and headspace volumes in each bottle and Henry's Law constants (Wilhelm et al., 1977). Anomalous readings resulting from syringe wear, identified through replicate measurements on the same or immediately preceding and succeeding sampling days, were excluded from the reported dataset. Error was propagated through these calculations using estimates of measurement error from syringes $( \pm 0.1 \mathrm{~mL}$ for pipetting, $\pm 0.1 \mathrm{~mL}$ for $3 \mathrm{~mL}$ syringes, $\pm 0.01 \mathrm{~mL}$ for $1 \mathrm{~mL}$ syringes) and standard deviations in gas concentration measurements collected from each sampling day's standard curve measurements.

\section{Substrate measurements during incubations}

Standard and sample dilutions for the methanol, TMA and ethanol substrates were prepared using analytical grade reagents and distilled water that had all been sparged of background volatile organic molecules (VOMs) with helium $(\mathrm{He})$ for $1 \mathrm{~h}$ at a rate of $100 \mathrm{~mL} / \mathrm{min}$ for every $1 \mathrm{~L}$ of solution. Analyte VOMs were likewise sparged from 1:1000 diluted liquid incubation samples using a Solatek autosampler along with a Tekmar Stratum purge and trap system outfitted with a K-type trap and quantified against a $10^{-5}$ to $10^{-8}$ calibration curve of standard dilutions on an Agilent 6850 GC (Stabilwax Crossbond Carbowax PEG capillary column, $30 \mathrm{~m} \times 0.25 \mathrm{~mm}$ ID $\times 0.5 \mu \mathrm{m})$ (Restek Chromatography Products, Bellafonte, PA) coupled to an Agilent 5975C mass spectrometer (MS) selectively monitoring ions in scan mode of $\mathrm{m} / \mathrm{z} 32,43$, and 45 for methanol, acetone, and isopropanol, respectively. TMA measurements were performed according to manufacturer's recommendations employing an Rxi-624Sil capillary GC column $(30 \mathrm{~m} \times 0.25 \mathrm{~mm}$ ID $\times 1.4 \mu \mathrm{m})$ (Restek Chromatography Products, Bellafonte, PA). Briefly, $0.5 \mu \mathrm{l}$ of $1000 \times$ diluted well fluid sample was injected directly into a 6850 Agilent GC, outfitted with a non-tapered injection port liner

Table 1 | Chemo-physical formation water characteristics and DNA content of the studied wells.

\begin{tabular}{|c|c|c|c|c|c|c|c|c|}
\hline Well & Fracture history & Times fractured & $\mathbf{p H}$ & $\begin{array}{l}\text { Alkalinity } \\
\text { (meq.liter }^{-1} \text { ) }\end{array}$ & {$\left[\mathrm{Cl}^{-}\right](\mathrm{M})$} & {$\left[\mathrm{Na}^{+}\right](\mathrm{M})$} & $\mathrm{CH}_{4} \mathrm{OH}(\mathrm{mM})$ & [DNA] $\left(\mathbf{n g ~ L ^ { - 1 } )}\right.$ \\
\hline A3-11 & Slick water and foam fractured & 3 & 6.97 & 10.6 & 1.72 & 1.26 & 16 & 1500 \\
\hline $\mathrm{B} 1-12$ & Foam fractured & 1 & 6.56 & 12.5 & 1.51 & 1.13 & 0.1 & 4750 \\
\hline C1-12 & Foam fractured & 1 & 6.69 & 13 & 1.73 & 1.29 & 4 & 1000 \\
\hline
\end{tabular}

For more detailed information about the well water chemistry see Supplementary Tables S1, S2. 
packed with deactivated glass wool (part\# 5062-3587, Agilent Technologies, Santa Clara, CA) and programmed with a 12:1 split ratio. Detection of TMA was performed using an Agilent 5975C MS in scan mode monitoring the diagnostic ion of $58 \mathrm{amu}$.

Concentrations of total free amino acids (as a yeast extract proxy) and ammonium in $5 \times$-diluted samples were measured at the Molecular Structure Facility of the University of California Davis using a Hitachi L-8800 amino acid analyzer.

\section{ILLUMINA MiSeq SEOUENCING OF 16S rRNA GENES: MICROBIAL DIVERSITY AND RELATIVE ABUNDANCE IN WELL WATER AND INCUBATION EXPERIMENTS}

DNA from the initial well water and incubation experiments were extracted according to Wuchter et al. (2004) and the total DNA was quantified fluorometrically using a Quant-iT ${ }^{\mathrm{TM}}$ PicoGreen ${ }^{\circledR}$ dsDNA Reagent (Invitrogen). The V4 region of the $16 \mathrm{~S}$ rRNA gene was amplified with universal prokaryotic primers modified from Caporaso et al. (2012). The same reverse primer 806r was used, but in combination with the 4 bp-shorter forward primer 519f ( $5^{\prime}$-CAGCMGCCGCGGTAA-3') ( $\varnothing$ vreas et al., 1997), to increase the potential coverage of archaeal sequences (Wang and Qian, 2009). The theoretical coverage of the slightly modified primer combination was $88.1 \%$ of bacterial and $90.5 \%$ of archaeal $16 \mathrm{~S}$ rDNA sequences available in the greengenes database (DeSantis et al., 2006) according to a primer coverage test using TestPrime 1.0 (Klindworth et al., 2013), as opposed to, respectively, 87.5 and $58.4 \%$ without modification of the forward primer. The formation of newly formed products was followed in real time using a Realplex quantitative PCR system (Eppendorf, Hauppauge, NY) and reagents (with the exception of primers) according to Coolen et al. (2009). The annealing temperature was set to $61^{\circ} \mathrm{C}$ and reactions were stopped in the exponential phase after 25-30 cycles. To minimize the formation of artifacts such as primer dimers, $10^{8}$ copies were subject to a second amplification reaction with the same region-specific primers that included the Illumina flowcell adapter sequences as well as the pad regions after Caporaso et al. (2012). The reverse amplification primer now also included a unique 12 base Golay barcode sequence (Caporaso et al., 2012) to support pooling of the samples. The second qPCR run was stopped after only 12 cycles when all samples reached the end of the exponential phase. The quality of the PCR products was verified by agarose gel electrophoresis and equimolar amounts of the barcoded PCR products were pooled and purified using the AMPure ${ }^{\circledR X P}$ PCR purification kit (Agencourt Bioscience Corp., Beverly, MA). Four hundred nanogram of the mixed and purified barcoded amplicons was subject to subsequent Illumina MiSeq sequencing using the facilities of Selah Genomics (Greenville, SC).

\section{Quality filtering of reads, OTU picking, and taxonomic assignments}

The quality scores associated with each base call for each read were used to determine the portion of each Illumina read that was of acceptable quality. Reads were first trimmed to $120 \mathrm{bp}$ to avoid sequencing errors toward the end of the reads, and the minimal acceptable Phred quality score was set to 30 during demultiplexing of Fastq sequence data using the split_libraries_fastq.py script in QIIME 1.6.0 (Caporaso et al., 2010a). Furthermore, reads were discarded when they contained an $\mathrm{N}$ character in their sequence or barcode. The pick_otus_through_otu_table.py workflow in QIIME with default settings was used to generate an OTU table in biom format. For example, this command with default settings assigned sequences to OTUs at $97 \%$ similarity and used the RDP classifier to assign taxonomic data to each representative sequence. Then, sequences were aligned using PyNAST (Caporaso et al., 2010b) against the greengenes database and a Newick format phylogenetic tree was built for subsequent UniFrac diversity measurements. A matrix of OTU abundance in each sample with meaningful taxonomic identifiers for each OTU in biom format was assembled from the taxonomic assignments and the OTU map using default settings as the final step of the pick_otus_through_otu_table.py workflow.

\section{Alpha rarefraction and beta diversity}

Alpha rarefaction was performed in QIIME using the script make_rarefraction_plots.py with default parameters and using the Phylogenetic Diversity, Chaol, and observed species metrics. For beta diversity analysis we executed the jackknifed_beta_diversity.py workflow script in QIIME, which used jackknife replicates to estimate the uncertainty in principal coordinate analysis (PCoA) plots and hierarchical clustering of microbial communities. This script executed the following steps: (a) Computed a beta diversity distance matrix from the full OTU table (b), produced an Unweighted Pair Group Method with Arithmetic mean (UPGMA) tree from full distance matrix, (c) and rarefied OTU tables, (d) computed distance matrices from rarefied distance matrices, (e) compared rarefied UPGMA trees and determines jackknife support for tree nodes, (f) computed principal coordinates on each rarefied distance matrix, and (g) compared rarefied PCoA plots from each rarefied distance matrix. In this step, the jackknifed replicate PCoA plots were compared to assess the degree of variation from one replicate to the next. This variation was displayed by drawing confidence ellipsoids around the samples represented in the PCoA plots.

The diversity of bacteria and archaea in the initial well waters and incubations was furthermore analyzed using domain-specific primers targeting the entire $16 \mathrm{~S}$ rDNA-V4 region. The resulting 465-bp-long bacterial and 396 bp-long archaeal amplicons were analyzed by denaturing gradient gel electrophoresis (DGGE) (Muyzer et al., 1993) and phylogenetic analysis of capillary sequenced (trimmed to $384 \mathrm{bp}$ ) individual DGGE fragments. The taxonomic information based on the longer DGGE sequences was compared with the taxonomy of the numerically most abundant OTUs from the shorter Illumina reads. Methodological details of the PCR/DGGE/capillary sequencing approach can be found in the Supplementary Info. Sequences obtained in this study were deposited to Genbank under accession numbers KC262274-KC262335 for the sequenced DGGE bands and KF72889-KF728946 for the described and discussed Illumina reads. See also supplementary information for further details.

\section{RESULTS}

\section{WELL WATER CHEMISTRY}

The extant water chemistry varied slightly between the wells (Table 1). In all three wells sulfate, nitrate, and phosphate were 
below the detection limit $(<0.10 \mathrm{mM})$. Salinities ranged between 8 and $10 \%$. Methanol concentrations differed substantially between the three wells. The highest methanol concentration was measured in the A3-11 well water $(16 \mathrm{mM})$, while methanol concentrations were four times lower in C1-12 (4 mM), and 160 times lower in B1-12 well water $(\sim 0.1 \mathrm{mM})$. See Supplementary Tables $\mathrm{S} 1, \mathrm{~S} 2$ in the supplementary info for detailed information about the analytical well water chemistry and gas composition. It is important to note that all three wells were likely sampled during a period of large flowback water production following hydraulic fracturing several months beforehand (see Figure 2; water data from A3-11 are not available for first 6 months of production). Gas and water production profiles from B1-12 and C1-12 were similar, whereas those for A3-11 were an order of magnitude smaller. Unless there were much lower formation water saturations in the A3-11 area that proportionally undermined biogenic gas generation therein, such a decline in both fluid profiles relative to the two other wells insinuates a poorer completion (i.e., less well-reservoir contact creation) in A3-11. Lack of formation water dilution may in turn explain the elevated methanol concentration measured in the waters recovered from that well.

\section{PROKARYOTIC COMMUNITIES IN INITIAL WELL WATERS}

The DNA concentration was highest (4750 $\mathrm{ng} \mathrm{L}^{-1}$ ) in B1-12 well water, followed by $1500 \mathrm{ng} \mathrm{L}^{-1}$ in $\mathrm{A} 3-11$, and lowest (1000 ng L ${ }^{-1}$ ) in the C1-12 well water (Table 1) and extracted DNA served as template for molecular analyses. On average $14,533 \pm 6087$ high quality Illumina reads with a quality score cut-off of 30 were recovered from the initial well waters. Using a $97 \%$ sequence similarity cut-off, the total number of OTUs was twice as high in C1-12 (336 OTUs) as compared to initial well waters of A3-11 (163 OTUs) and B1-12 (164 OTUs). Rarefraction $\alpha$ diversity measures in the initial well waters using the phylogenetic diversity metric showed that the rarefraction curves almost reached a plateau, indicating that it becomes less likely to identify new phylotypes with greater sequencing depth (Supplementary Figure S2, Supplementary Table S3). PCoA jackknifing using weighted UniFrac distance metric showed that the prokaryotic diversity was most similar between A311 and C1-12 (Figure 3A). The first and second axes of the PCoA analysis explained 61.9 and $16.1 \%$, respectively, of the prokaryotic diversity variance among the three initial well waters (Figure 3A).

\section{Bacterial diversity and relative abundance}

In all three wells $>99 \%$ of the Illumina reads could be assigned with the RDP classifier in QIIME to the bacterial domain (Figure 3B). Bacteroidetes, Proteobacteria, Firmicutes and a group of unclassified bacteria comprised $>96 \%$ of the Illumina reads in the studied well waters. The unclassified bacteria were most abundant in B1-12 and lowest in C1-12 (Figure 3). A single OTU with 91\% similarity to the Arctic bacterium NP25 (Perreault et al., 2007) represented the majority of the unclassified bacteria, being highest (97\% of the unclassified bacteria) in B1-12 (Supplementary Figure S3). This OTU represented $45 \%$ of the unclassified bacteria in $\mathrm{C} 1-12$, where the diversity of unclassified bacteria was highest (Supplementary Figure S3).

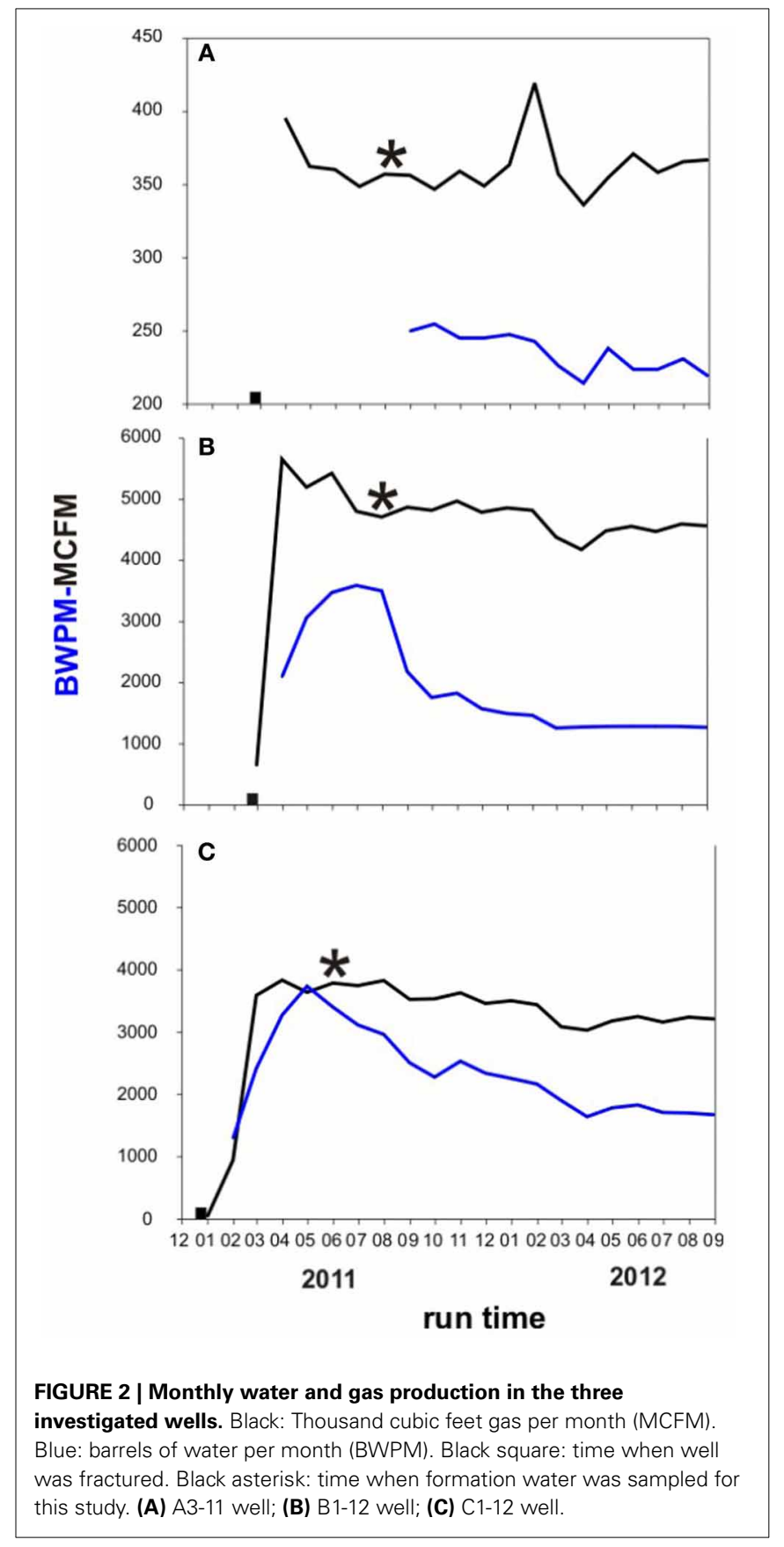

Bacteroidetes, Proteobacteria, and Firmicutes, which comprised more than $1 \%$ of the total reads shared $92-100 \%$ sequence similarity to previously described cultures of mesophilic and moderately halophilic bacterial species (Table 2 ). The majority of Bacteroidetes and Firmicutes showed highest sequence similarity with strictly anaerobic, fermenting bacteria, which can utilize a wide variety of organic compounds such as sugars, peptides, amino acids, organic acids, or alcohols. The dominant Firmicutes were most similar to described species of the order Halanaerobiales, including Halanaerobium hydrogeniformans (Brown et al., 2011), Haloanaerobium congolense (Ravot et al., 1997), Halocella cellulolsilytica (Simankova et al., 1993), 


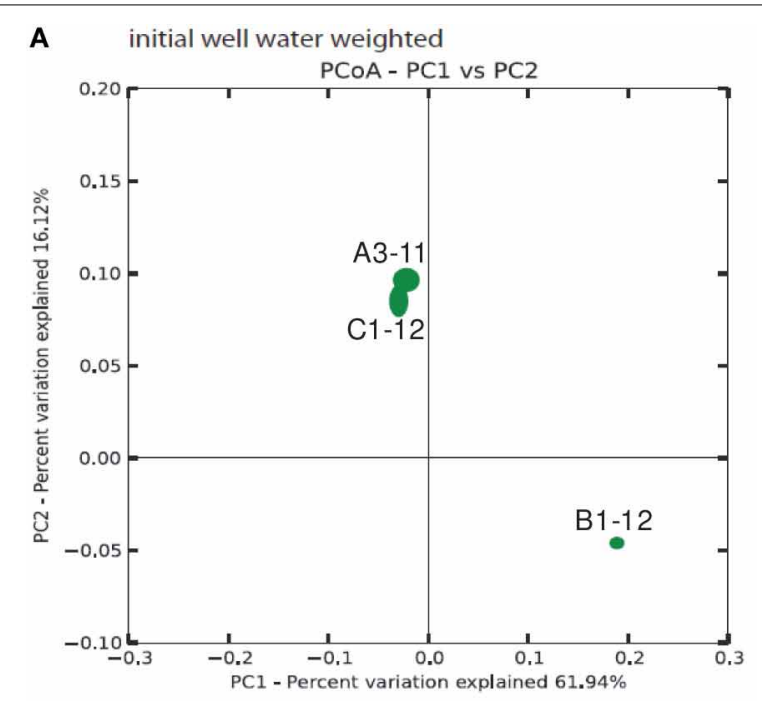

B

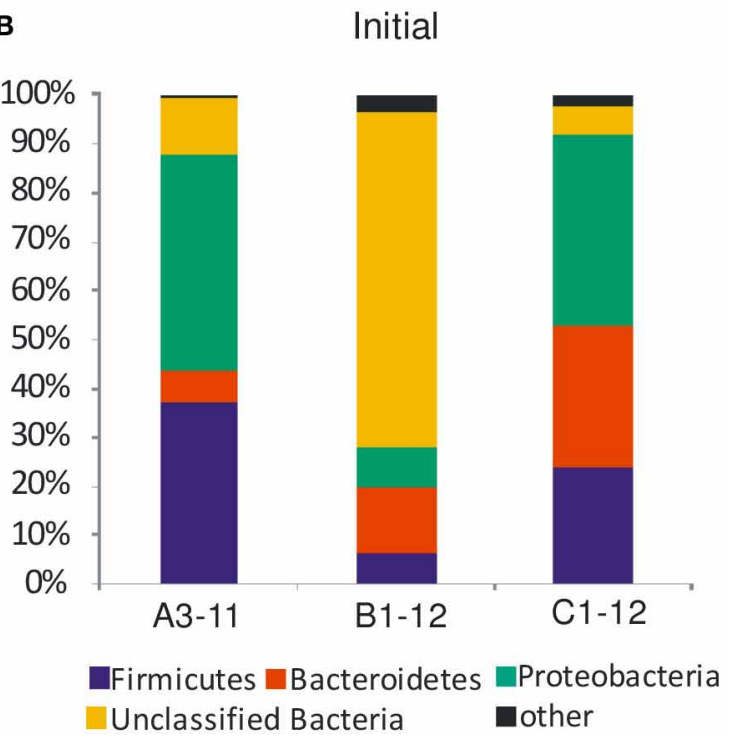

FIGURE 3 | General overview of the prokaryotic diversity in the initial well waters. (A) Jackknifed PCoA plot of initial well water samples with weighted Unifrac. Shown is a plot of the first two principal coordinate axes, which combined explain $78 \%$ of the variation. Ellipses represent the interquartile range of the distribution of points among the 10 jackknifed replicates. (B) Relative abundance (\% of Illumina reads) of the major bacterial phyla. A more detailed overview of the most abundant unclassified bacteria is shown in Supplementary Figure S3. "Other" euryarchaota which comprised up to $1.3 \%$ of total Illumina reads with the remainder being less abundant bacteria (mainly OP9 and Spirochaeta).

Orenia marismortui (Rainey et al., 1995), and O. salinaria (Mouné et al., 2000) (Table 2). OTUs most similar to Marinilabilia salmonicolor (Nakagawa and Yamasato, 1996) and Cytophaga sp. AN-B14 (Daffonchio et al., 2006) comprised the most abundant Bacteroidetes (Table 2). The most abundant OTUs belonging to the $\delta$ - and $\varepsilon$-Proteobacteria were related to sulfur-, sulfate-, iron-, or nitrate-reducing bacteria (Table 2) and a single OTU with $100 \%$ sequence similarity to the nitrate-reducing
Acrobacter marinus (Kim et al., 2010) greatly outnumbered other $\varepsilon$-Proteobacteria as well as the $\delta$-Proteobacteria in all three wells (Table 2). Bacterial OTUs that represented more than $1 \%$ of the Illumina reads were also recovered via capillary sequencing of individual DGGE bands (Supplementary Table S4) and the percentage sequence similarity with the most closely related cultivated species from GenBank is shown in Supplementary Table S5. However, DGGE is at best semi-quantitative and does not provide accurate information about the relative abundance of bacterial phyla and individual OTUs in the initial well waters.

\section{Archaea diversity and relative abundance}

Archaeal sequences represented only $0.15,0.46$, and $1.07 \%$ of the total Illumina reads, respectively, in A3-11, B1-12, and C112 and are part of the "other" in Figure 3B. All detected archaeal sequences belonged to the phylum Euryarchaeota. The majority (20) of archaeal OTUs showed $83-100 \%$ sequence similarity to uncultured environmental clones, and $91 \%$ sequence similarity or less to cultured species (see Supplementary Table S4, for details). However, Illumina sequencing also revealed two archaeal OTUs with $>99 \%$ sequence similarity to the methylotrophic methanogens Methanolobus profundi (Mochimaru et al., 2009) and Methanohalophilus halophilus (Wilharm et al., 1991). Two additional archaeal OTUs were most closely related to the hydrogenotrophic methanogens Methanocalculus halotolerans (Ollivier et al., 1998) and Methanoplanus limicola (Wildgruber et al., 1982). OTUs with the same most closely related GenBank sequences were also recovered from sequenced archaeal DGGE bands spanning the entire V4 region. A phylogenetic tree of the archaeal phylotypes recovered with the DGGE approach was prepared since the majority of the archaeal sequences are only distantly related to cultivated species (Supplementary Figure S4).

\section{INCUBATION EXPERIMENTS \\ Total methane yields in the different treatments}

Detectable amounts of methane accumulated in the headspace of incubation bottles with all three well waters even without the addition of substrates (i.e., bottles referred to as no substrate) (Figure 4). The highest stable methane yields without substrate addition were measured in incubations with A3-11 well water followed by $\mathrm{C} 1-12$ and being lowest in B1-12. The addition of powdered shale, acetate, and propionate did not result in increased methane yields relative to incubations without substrate addition for any well (Figure 4). The addition of glucose had a negative effect on methane generation for all three wells. Formate addition stimulated methane generation only in the B1-12 well water. The addition of yeast extract had a definite stimulatory effect on methane generation in the B1-12 and C1-12 well waters. The highest methane yields were measured with TMA and methanol as substrates with five (A3-11) to ten (B1-12) fold higher methane yields in the headspace than without substrate addition (Figure 4).

\section{Methanol and TMA consumption}

Methanol and TMA were readily consumed by the microbial community in the incubation experiments and resulted in the 
Table 2 | Relative abundance (\% of total Illumina reads) OTUs recovered from the initial formation waters of the A3-11, B1-12, and C1-12 wells.

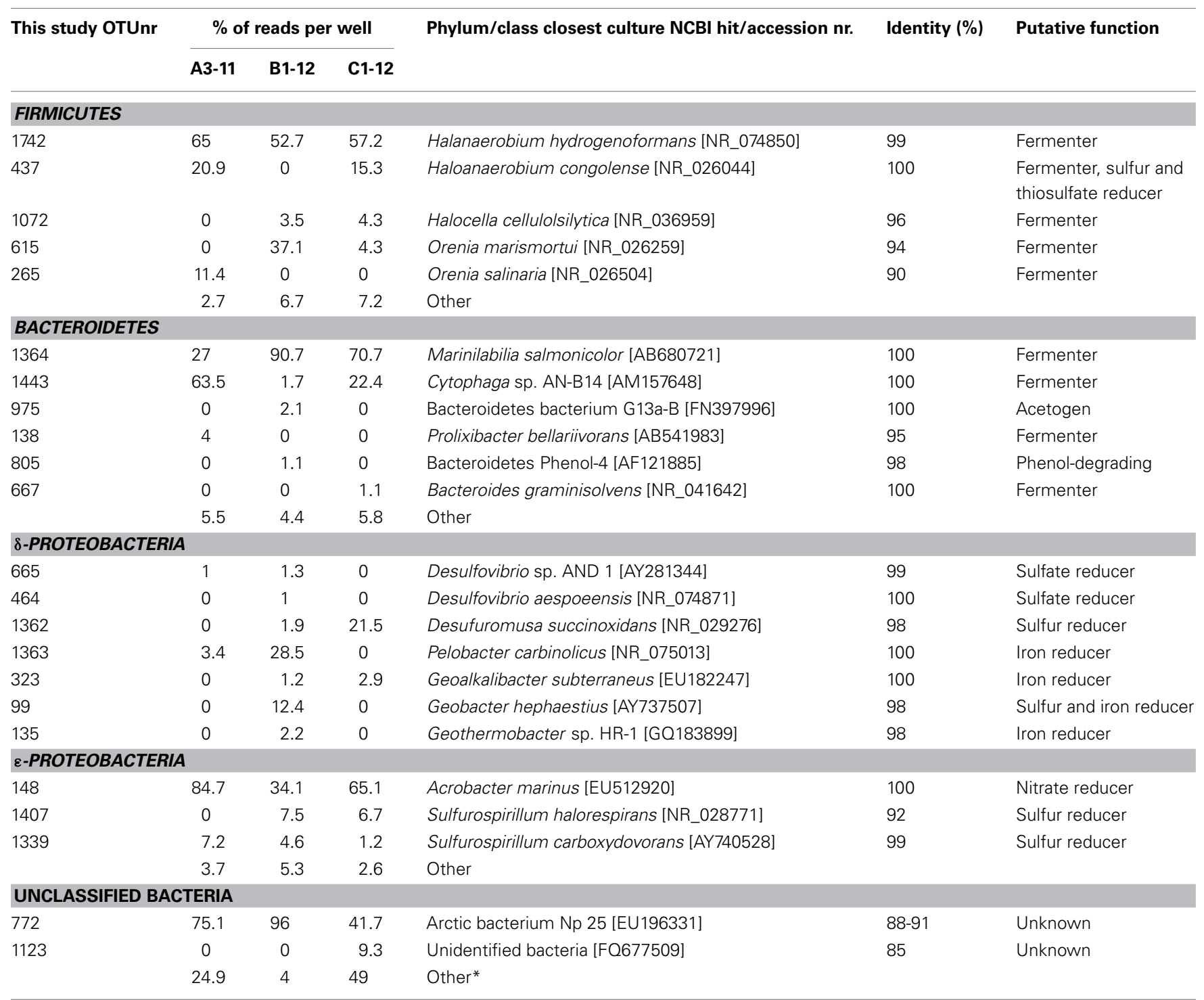

Other reads which represent less than $1 \%$ of the reads in the major listed phyla. Other* (unclassified reads; see detailed information in Supplementary Figure S3).

highest methane yields. The utilization of methanol by methylotrophic methanogens follows according to reactions (1) and (2) as shown in Table 3. A molar methanol to methane conversion ratio $\left[\mathrm{MCR}_{\mathrm{MeOH}}\right]$ of $1-1.33$ would be expected (Table 3 ) if the methanol present in incubations with or without methanol addition were utilized completely. However, the actual measured methane accumulation in the headspace was sometimes substantially lower, suggesting that not all the methanol consumed in the no-substrate and methanol incubations was converted to methane, or that methane was consumed anaerobically in some incubation bottles (Table 4).

TMA was tested as a methanogenic substrate for incubations with A3-11 and B1-12 well waters and resulted in methane yields comparable to those from methanol additions. TMA is utilized by methanogens according to reaction (3) as shown in Table 3. Given the stoichiometry of reaction (3), complete TMA consumption would theoretically result in a TMA to methane conversion ratio [MCR $\left.\mathrm{MMA}_{\mathrm{TM}}\right]$ of 0.45 . The measured methane yields, when corrected for methanol-derived methane productions, are in good agreement with theoretical expectations suggesting that most consumed TMA was converted to methane. See Supplementary Figure S5 for detailed information about the methanol and TMA consumption and methane accumulation in the A3-11 well over the course of incubation.

\section{Hydrogen dynamics in the different treatments}

Gradual accumulation of hydrogen in excess of $200 \mu$ moles was detected in the headspace of all three well waters when incubated with glucose and formate. Only formate addition 


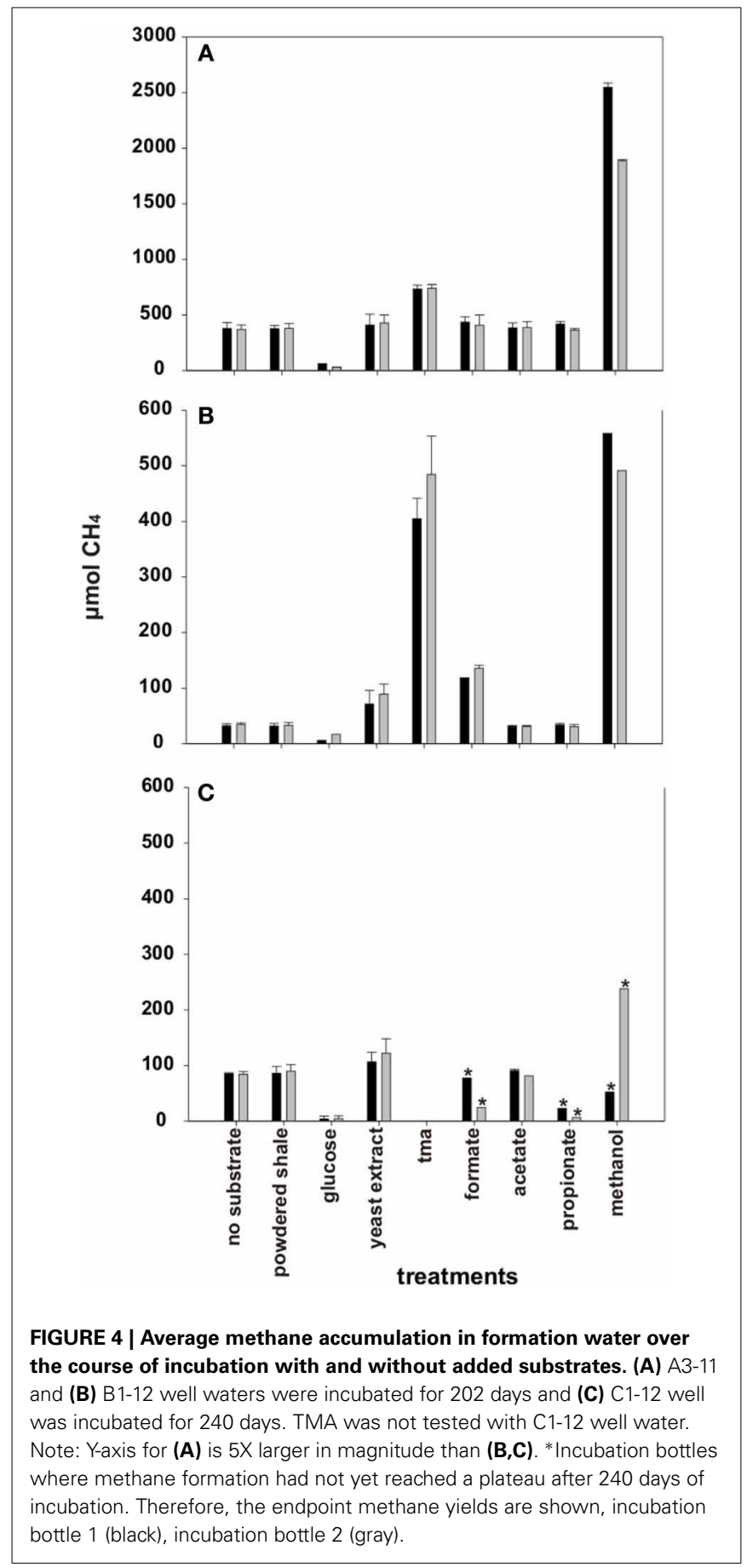

to B1-12 well water resulted in hydrogen consumption and concomitant methane production (Table 4). No hydrogen consumption was observed in well waters incubated with glucose, and methane accumulation was minor in all three well waters over the entire course of incubation (Figures 4 and Supplementary Figure S6). A lower amount of hydrogen $(15-34 \mu$ moles $)$ was detected in the headspace of well water incubated with yeast-extract (Table 4) (yeast extract consumption; Supplementary Figures S6, S7). Incubation with the
Table 3 | Methanogenic consumption of methanol (reactions 1 and 2), TMA (reactions 3 ), and hydrogen (reaction 4 ) and molar conversion ratios.

\begin{tabular}{ll}
\hline Reaction & $\begin{array}{l}\text { Molar conversion } \\
\text { ratio (MCR) }\end{array}$ \\
\hline (1) $\mathrm{CH}_{3} \mathrm{OH}+\mathrm{H}_{2} \rightarrow \mathrm{CH}_{4}+\mathrm{H}_{2} \mathrm{O}$ & 1.0 \\
(2) $4 \mathrm{CH}_{3} \mathrm{OH} \rightarrow 3 \mathrm{CH}_{4}+\mathrm{CO}_{2}+2 \mathrm{H}_{2} \mathrm{O}$ & 1.33 \\
(3) $4\left(\mathrm{CH}_{3}\right) 3 \mathrm{~N}+6 \mathrm{H}_{2} \mathrm{O} \rightarrow 9 \mathrm{CH}_{4}+3 \mathrm{CO}_{2}+4 \mathrm{NH}_{4}+$ & 0.45 \\
(4) $4 \mathrm{H}_{2}+\mathrm{CO}_{2} \rightarrow \mathrm{CH}_{4}+2 \mathrm{H}_{2} \mathrm{O}$ & 4.0 \\
\hline
\end{tabular}

other substrates did not result in detectable accumulation of hydrogen.

Hydrogenotrophic methanogens utilize hydrogen according to reaction (4) as shown in Table 3. According to this stoichiometry, for every mole of methane produced, four moles of hydrogen must be consumed. When corrected for background methane production (as measured from the no-substrate bottles), for example, in the C1-12 well between 22 and $37 \mu$ moles of methane was detected in well waters incubated with yeast extract. Such a methane yield would correspond to a range of 88 to $148 \mu$ moles of hydrogen consumption. This is far greater than the measured hydrogen accumulations (Table 4), suggesting that part of the produced hydrogen escaped detection due to quick turnover by hydrogenotrophic methanogens in the incubations.

\section{Effect of surface area}

Methane accumulated substantially earlier in incubations with powdered shale compared to well waters without substrate addition (data only shown for C1-12 well, Figure 5). Despite the difference in initial methane production rates, the amount of methane production with or without the addition of shale had stabilized at nearly identical methane yields toward the end of the incubation period. Approximately $25 \mu$ moles of methane that was produced in C1-12 well water with sterile pulverized shale might have been consumed microbially as evident from the difference in the amount of methane after 30 and 240 days of incubation (Figure 5).

\section{PROKARYOTIC COMMUNITY DETECTED IN THE INCUBATION EXPERIMENTS}

\section{Bacteria}

Most bacterial OTUs found in the incubation experiments were also present in the initial well water (Supplementary Figure S8). In the incubation experiments the dominant Firmicutes were OTUs with highest sequence similarity to Halanerobium hydrogeniformans, H. congolense, Orenia marismortui, and O. salinaria. OTUs with highest sequence similarity to Marinilabilia salmonicolor and Prolixibacter bellariivorans comprised the most abundant Bacteroidetes. The Proteobacteria were predominated by OTUs with highest sequence similarity to Acrobacter marinus, Pelobacter carbinolicus, Sulfurospirillum sp., and Desulfovibrio sp. (Supplementary Figure S8). However, the relative abundance of these microbial populations was found to differ significantly between treatments (ANOSIM; $P=0.024 ; r=0.2658$ ), which is 
Table 4 | Methanogenic substrate consumption and corresponding methane accumulation.

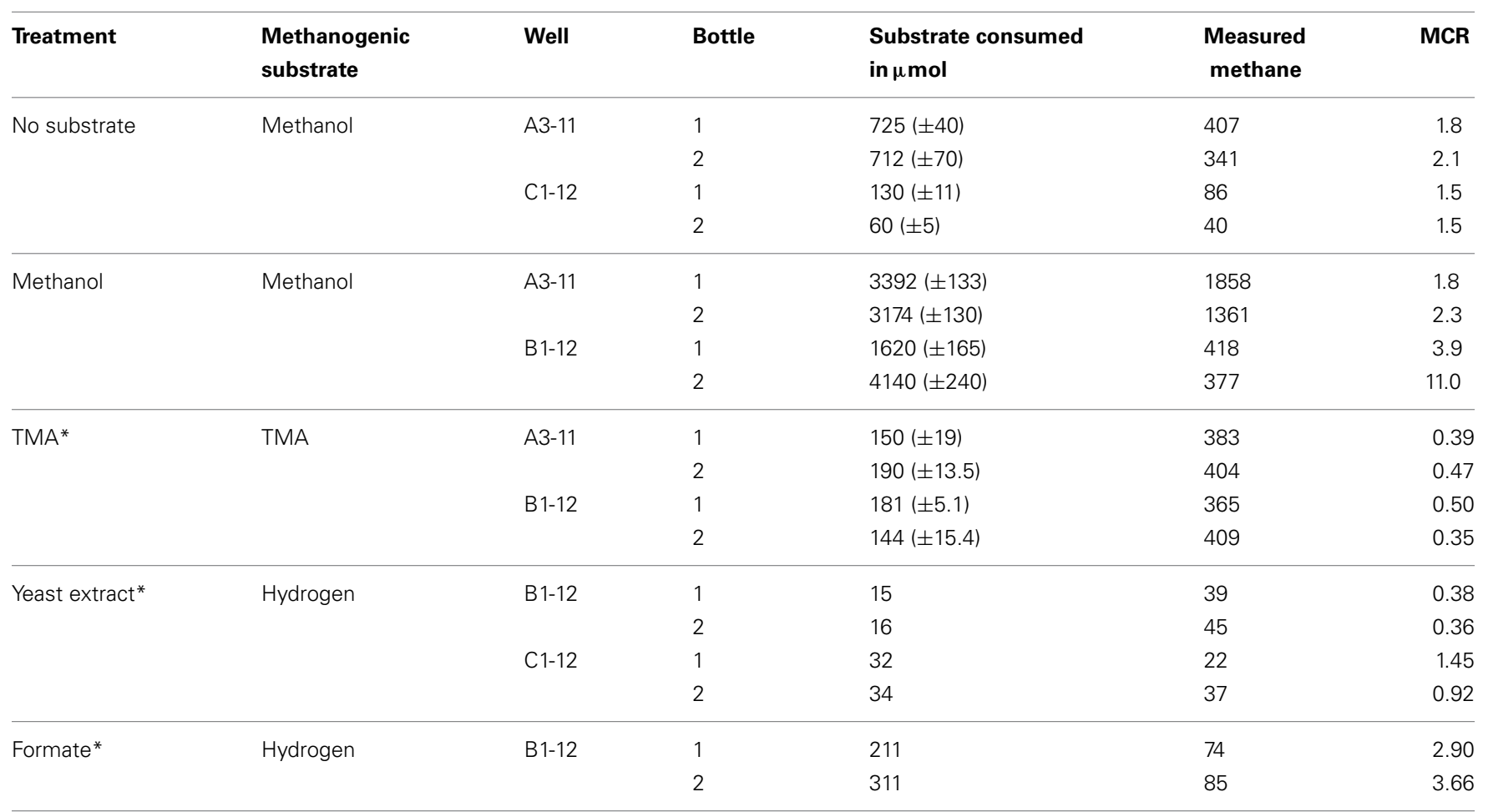

*Methane yields corrected for methane derived from methylotrophic methanogens after subtraction of the "no substrate" background. See Supplementary Figures S5, S6 for comparison. No MCR $\mathrm{MeOH}_{\mathrm{H}}$ could be calculated for the B1-12 "no substrate" and C1-12 "methanol" experiments. The low initial methanol concentration in the B1-12 well reached the detection limit at the time of sampling in the incubation experiment. The C1-12 well water incubated with methanol addition did not reach a methane plateau at the end of the experiments (see Figure 4). Error for the methane measurement was on average between 1.1 and $2.7 \mu$ mol and for hydrogen measurements 0.1 and $1.4 \mu \mathrm{mol}$ in all incubations.

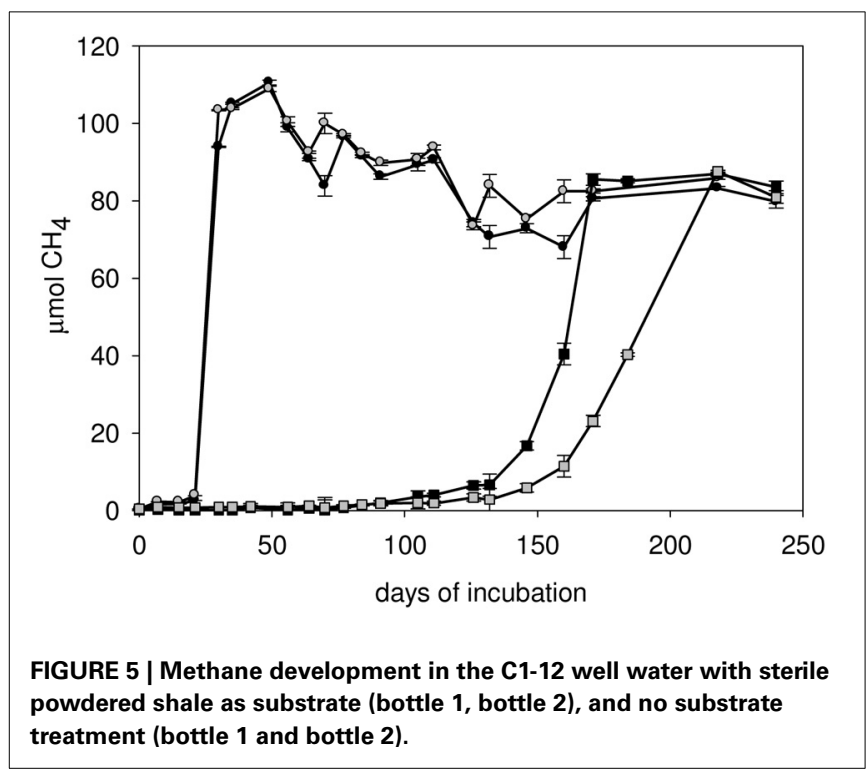

further visualized by the limited overlap between samples in the Jacknifed PCoA plot (Supplementary Figure S9).

In all three well waters the addition of phosphate and nutrients stimulated the growth of bacteria belonging to the
Firmicutes, reaching $>80 \%$ of the total bacterial Illumina reads (Supplementary Figure S8). Powdered shale had the largest effect on the microbial communities in C1-12 with a shift toward a predominance of Proteobacteria as compared to the incubations without substrate (Supplementary Figure S8). The addition of methanol stimulated Firmicutes in A3-11 and Proteobacteria in the two other well waters compared to no substrate addition. Glucose had little effect on bacterial communities in A3-11 and C-1-12, but stimulated Proteobacteria in B112. Yeast extract, TMA and formate stimulated the growth of unclassified bacteria, notably a bacterium with highest sequence similarity to the uncultured Arctic bacterium NP25, in the majority of well water incubations. Acetate and propionate stimulated the growth of Proteobacteria in B1-12 and C1-12, while the relative abundance of uncultured bacteria was stimulated in A3-11 upon the addition of acetate (Supplementary Figure S8).

\section{Archaea}

OTUs with $>99 \%$ sequence similarity to the methylotrophic methanogens Methanolobus profundi and Methanohalophilus halophilus, were detected in all incubation experiments with all tested substrates. Sequences with $99 \%$ sequence similarity to the hydrogenotrophic methanogen Methanoplanus limicola were found in the yeast extract treatment in B1-12 
and C1-12 well waters. Sequences with $100 \%$ similarity to another hydrogenotrophic methanogen, Methanocalculus halotolerans, were found only in formate-treated B1-12 well water. Archaeal OTUs detected in the initial well water without close cultured representatives were not detected in the incubation experiments with one exception; archaeal OTU O5 was found in methanol-treated B1-12 well water (Supplementary Table S5). Despite methane formation and the presence of OTUs related to methanogenic archaea, the relative abundance of archaeal Illumina reads did not increase in any of the incubations compared to the initial.

\section{DISCUSSION \\ PRODUCTION WATER CHARACTERISTICS AND IMPLICATION ON MICROBIAL COMMUNITY}

The methane-producing zone in the Antrim Shale formation contain formation waters whose temperature and salinity range is suitable for mesophilic moderately halophilic microorganisms (Martini et al., 1996; Waldron et al., 2007). Nonetheless, as mentioned earlier, the three wells were all recently fractured and their production water profiles suggest that water samples collected for this study might have entrained volumetrically significant amounts of hydraulic fracture flowback fluid, with an especially large proportional contribution implied for the A3-11 well. Thus, the well water microbial community identified in our survey most likely represents a mixture of indigenous shale communities and allochthonous species, which were introduced to these reservoirs during drilling and fracturing procedures (Struchtemeyer et al., 2011; Struchtemeyer and Elshahed, 2012). The residence time of the introduced drilling mud and fracturing fluid into the shale formation impacts the formation water chemistry and biology. During the drilling procedure large volumes of drilling mud are often lost in the shale formation (Gray et al., 1980; Grace, 2007) and only 30-70\% of fracturing fluids injected into wells are recovered in the flowback waters (Veil, 2010). A recent study on hydraulic fractured thermogenic wells in the Barnett Shale (USA) showed that the concentration of salt, iron and total dissolved solids were higher in flowback water of a well that had been in contact with fracturing fluids for 2 months compared to a well with a much shorter contact time of $24 \mathrm{~h}$ (Struchtemeyer and Elshahed, 2012). The authors suggested that the differences in the bacterial community in the flowback water of the two wells might be influenced by the different time intervals ( 2 month vs. $24 \mathrm{~h}$ ) between fracturing and flowback at the two sites (Struchtemeyer and Elshahed, 2012). Our data support these findings. Namely, the prokaryotic beta diversity in the two wells (A3-11 and C1-12) with a longer contact time of fracturing fluid was more similar than in B1-12 with a shorter contact time of fracturing fluid as indicated by the differences in methanol concentration. In addition to methanol, cellulose, lignosulfonates, and sugar-based polymers are components of fracturing fluids and drilling muds (Caenn et al., 2011, www. fracfocus.org). For example, guar gum or hydroxyethyl cellulose is frequently used in fracturing fluids to thicken the water in order to suspend the sand. These additives might explain the presence of an active fermenting microbial community in the production water as observed in the incubation experiments by the quick utilization of fermentable substrates such as yeast extract and glucose. The prominent heterotrophs in the production water and the incubation experiments were members of the genus Haloanaerobium (Firmicutes) and the genera Marinilabilia and Cytophaga (Bacteroidetes). Haloanaerobium species usually ferment saccharides and produce $\mathrm{H}_{2}, \mathrm{CO}_{2}$, and $\mathrm{C}_{2}$ compounds (mainly acetate and sometimes ethanol, as was detected in the glucose treated incubations) (Ollivier and Cayol, 2005). One prominent OTU was closely related to Marinilabilia salmonicolor (Nakagawa and Yamasato, 1996), a bacterium capable of utilizing cellulose and complex carbohydrate. Additional sequences were related to Cytophaga, Dechloromonas, and Pseudomonas and members of these genera have been reported to be capable of growing on crude oil, benzene, xylene, and toluene (Prince, 2005), and might play an important role in the degradation of refractory OC in the Antrim shale. Also, the unclassified bacteria constitute a substantial fraction of the total bacterial reads, especially in the B1-12 well. These bacteria might also be capable of utilizing complex organic shale matter. Furthermore, a number of archaeal OTUs unaffiliated with known methanogenic groups were detected in the initial production water samples, which were not subsequently detected during the bottle incubations. These euryarchaeota may possess non-methanogenic metabolisms and also be involved in bitumen degradation in situ.

\section{METHANOGENIC CAPABILITIES IN INCUBATION EXPERIMENTS}

Methanol was quickly utilized in the incubation experiments and high concentrations of added methanol did not inhibit methylotrophic methanogenesis suggesting that the methanogenic community is well-adapted to high methanol concentrations most likely derived from the fracturing procedure since methanol is a standard ingredient in fracturing fluids. Halophilic methanogens generally utilize substrates such as methanol, methylamines, or dimethyl sulfide, which yields more free energy compared to acetate or hydrogen (Oren, 2001). This extra energy might be used for their osmoregulatory system to balance the energetic demands of the saline environment (Oren, 2001).

TMA was below detection limit in our formation waters suggesting that this compound plays a minor role in comparison to methanol as a substrate for methylotrophic methanogens in this environment. TMA could potentially be formed in formation water through fermentation of betaine, which is an osmoregulatory compound synthesized by some halophilic bacteria (Oren, 1990). The bacterial fermentation of betaine can yield acetate and TMA. Also, similar to coal matrices (Strąpoć et al., 2011) the organic-rich Antrim Shale might be a source of methylamines.

Acetate was not utilized by methanogens in any of the three analyzed well waters and we did not find any phylogenetic evidence for acetoclastic methanogens. This is in agreement with the finding that acetoclastic and hydrogenotrophic methanogens generally thrive in freshwater or lower salinity environments (Oren, 1999, 2001). Instead, hydrogenotrophic methanogens were detected in the initial well waters and after incubation with yeast extract. Hydrogenotrophic methanogens were also identified when formate was used as a substrate, but only in B1-12. 
Here, hydrogen was generated by fermentation and consumed concomitant with methane production. B1-12 incubated with formate yielded an OTU closely related to Methanocalculus halotolerans, the most halotolerant hydrogenotrophic methanogen known to date and capable of withstanding concentrations of up to $12 \% \mathrm{NaCl}$ (Ollivier et al., 1998). One OTU closely related to Methanoplanus limicola (Wildgruber et al., 1982) was detected in B1-12 and C1-12 well waters incubated with yeast extract. This methanogen tolerates salt concentrations between 0.4 and 5.4\% (Wildgruber et al., 1982), which is substantially lower than the salt concentration of $8-10 \%$ in our formation waters. Most likely this OTU represents a novel hydrogenotrophic methanogen with a higher salinity tolerance. Both hydrogenotrophic methanogens might possess different hydrogen affinities since the utilization of formate resulted in a 10-fold higher hydrogen concentration then the amount of hydrogen resulting from the fermentation of yeast extract. The OTU related to M. limicola, might be better adapted to grow at low hydrogen concentrations, whereas the OTU related to M. halotolerans, is capable of thriving at elevated hydrogen concentrations. This could be similar to methanogens from rice paddies, which grow slowly if at all at high hydrogen concentrations (Sakai et al., 2007).

The low methane generation in the glucose-treated incubations could be explained by an inhibition of the methanogenic community caused by the rapid depletion of nutrients and/or the decrease in $\mathrm{pH}$ from the accumulation of organic acid intermediates (Strąpoć et al., 2011) as a result of bacterial fermentation. The accumulation of ethanol caused by fermentation might also have had an inhibitory effect on the methanogens present in the glucose treatment.

The increase of mineral surface area greatly stimulated methane production rates as observed from formation waters that were incubated with sterile powdered shale. However, the addition of shale did not result in consistent increases in methane yield in the C1-12 well water, and the overall methane yield in the other two well waters was identical to the no substrate background. This suggests that over the course of incubation the bitumen in the powdered shale was not utilized by fermentative prokaryotes and did not yield substrates for the methanogenic communities. In contrast, a previous enrichment experiment showed that fermentative bacteria derived from Antrim well water could be enriched by using only water-soluble shale OM and subsequent methane accumulation was detected, demonstrating that methanogenic communities can be supported by using shale derived DOM as the only source of energy and carbon (Huang, 2008). Most likely our fermenting microbial community was adapted to the presence of easy degradable carbon compounds such as those stemming from the drilling and fracturing procedure, and was not adapted to degrade bitumen from the shale.

\section{METHANOL AND METHANE CONSUMPTION}

The discrepancy between the theoretically expected methane yields based on methanol consumption and measured methane yields requires non-methanogenic methanol-utilizing metabolisms, or the ability of anaerobic oxidation of methane to be present. This could be explained by OTUs related to methanolutilizing bacteria such as Geoalkalibacter subterraneus (Greene et al., 2009) present in the incubation experiments. Furthermore, some sulfate reducers are known to utilize methanol (Qatibi et al., 1991; Tarasov et al., 2011), and might be involved in methanol consumption. Also, the detected archaea without close cultured relatives, which were detected in the methanol incubation experiment, might possess the capability to utilize methanol.

The depletion of methane suggests anaerobic methane oxidation (AMO) at least in C1-12 well water incubated with powdered shale. Methane can be oxidized anaerobically by a consortium of methane-oxidizing archaea (ANME clusters), and sulfatereducing bacteria (SRB) (Knittel and Boetius, 2009). We did find sequences of SRB in our incubation experiments, however no ANME-related sequences were recovered despite a good coverage of the universal primers used to generate template DNA for Illumina sequencing. Although the archaeal partner involved in AMO was not found, the depletion of methane in some of the incubations and possible involvement of AMO is in agreement with previous geochemical evidence for anaerobic hydrocarbon oxidation in formation water of the western margin of the Antrim shale (Martini et al., 2003). The western margin formation water contains some of the highest sulfate concentrations relative to salinity in the Antrim shale (Walter et al., 1997), and C2 and $\mathrm{C} 3$ gasses are enriched in $\delta^{13} \mathrm{C}$ values, suggesting that anaerobe hydrocarbon oxidation occurred in the western margin (Martini et al., 2003).

The sulfate present in the formation water is most likely derived from the shale since a recent incubation-based study showed that water-soluble organic shale material sustains SRB (Huang, 2008). This is supported by our incubation experiments where a shift toward $\delta$ - and $\varepsilon$-Proteobacteria, which comprise many iron-, sulfur-, sulfate-, and nitrate reducers, was observed with the addition of powdered shale. Sulfate can be quickly utilized by SRB, which compete for hydrogen and other lowmolecular-weight substrates with methanogens. Recently, a study on formation water from wells along the northern production trend of the Antrim shale showed an increase in sulfate concentrations and SRB over the last two decades (Kirk et al., 2012). The authors explained these changes by ongoing processes driven by commercial gas production such as ground water inflow from the sulfate-rich Travers limestone, which is in contact with the Antrim shale (Kirk et al., 2012). It was furthermore suggested that this development could have negative implications for commercial gas production by creating conditions that favor growth of SRB (Kirk et al., 2012). These bacteria can compete with methanogens for substrate or, as indicated previously (Martini et al., 2003) and suggested in our study, SRB could be involved in AMO and responsible for loss of methane in the shale formation.

\section{CONCLUDING REMARKS}

Microbial community composition in closely spaced production wells can differ substantially due to local variation in both reservoir quality (e.g., lithology, matrix and natural fracture microstructure, fluid chemistry and saturation) and completion 
quality (e.g., hydraulic fracture design and fluid composition, well cleanup workflow, and subsequent production strategy). The microbial fermenting community in our study was capable of rapidly utilizing substrates, such as glucose and yeast extract, suggesting that they are well-adapted to decompose relatively labile OM including organic additives used in drilling and fracturing fluids. Hydrogenotrophic methanogens were detected, but the production waters from recently fractured wells appear to be dominated by methylotrophic methanogens, capable of utilizing high concentrations of methanol likely stemming from the fracturing fluids. Furthermore, we found that increased surface area stimulated methane production. However, a loss of methane over the course of incubation suggests that AMO also occurs in formation waters, which might constitute a substantial loss of methane in the shale formation.

\section{ACKNOWLEDGMENTS}

This study was conducted at Woods Hole Oceanographic Institution (WHOI) and Schlumberger Doll Research (SDR) with support from the Schlumberger Future of Research (FOR) proposal program and SDR Department of Reservoir Geosciences. We are grateful to Sean Silva and Carl Johnson for technical assistance with gas chromatography and to Dr. Chris Reddy for providing the anaerobic glove box at WHOI. We also thank John Miller, Linda Hasbrouck, and their colleagues at Presidium Antrim West LC who facilitated the collection and shipping of the water and core samples used in this study. Tracy J. Mincer was supported for this project from NSF CHE-OCE Award \# 1131415.

\section{SUPPLEMENTARY MATERIAL}

The Supplementary Material for this article can be found online at: http://www.frontiersin.org/journal/10.3389/fmicb. 2013.00367/abstract

\section{REFERENCES}

Arthur, J., Bohm, B., Coughlin, B. J., and Layne, M. (2008). Evaluating the Environmental Implications of Hydraulic Fracturing in Shale Gas Reservoirs. Tusla: ALL Consulting.

Brown, S. D., Begemann, M. B., Mormile, M. R., Wall, J. D., Han, C. S., Goodwin, L. A., et al. (2011). Complete genome sequence of the haloalkaliphilic, hydrogen-producing bacterium Halanaerobium hydrogeniformans. J. Bacteriol. 193, 3682-3683. doi: 10.1128/JB.05209-11

Caenn, R., Darley, H. C. H., and Gray, G. R. (2011). Composition and Properties of Drilling and Completion Fluids, 6th Edn. Oxford: Elsevier.

Caporaso, J. G., Kuczynski, J., Stombaugh, J., Bittinger, K., Bushman, F. D., Costello, E. K., et al. (2010a). QIIME allows analysis of high-throughput community sequencing data. Nat. Methods 7, 335-336. doi: 10.1038/nmeth.f.303

Caporaso, J. G., Bittinger, K., Bushman, F. D., DeSantis, T. Z., Andersen, G. L., and Knight, R. (2010b). PyNAST: a flexible tool for aligning sequences to a template alignment. Bioinformatics 26, 266-267. doi: 10.1093/bioinformatics/btp636

Caporaso, J. G., Lauber, C. L., Walters, W. A., Berg-Lyons, D., Huntley, J., Fierer, N., et al. (2012). Ultra-high-throughput microbial community analysis on the Illumina HiSeq and MiSeq platforms. ISME J. 6, 1621-1624. doi: 10.1038/ismej.2012.8

Coolen, M. J. L., Saenz, J. P., Giosan, L., Trowbridge, N. Y., Dimitrov, P., Dimitrov, D., et al. (2009). DNA and lipid molecular stratigraphic records of haptophyte succession in the Black Sea during the Holocene. Earth Planet. Sci. Lett. 284, 610-621. doi: 10.1016/j.epsl.2009. 05.029
Curtis, J. B. (2002). Fractured shale -gas systems. Am. Assoc. Pet. Geol. Bull. 86, 1921-1938. doi: 10.1306/61EEDDBE-173E-11D7-8645000102C1865D

Daffonchio, D., Borin, S., Brusa, T., Brusetti, L., van der Wielen, P. W. J. J., Bolhuis, H., et al. (2006). Stratified prokaryote network in the oxic-anoxic transition of a deep-sea halocline. Nature 440, 203-207. doi: 10.1038/nature04418

DEQ. (2012). Department of Environmental Quality, Michigan. Office of Oil, Gas and Minerals. Available online at: http://www.michigan.gov/documents/deq/ MICHIGANOILGASMAP4116007.pdf

DeSantis, T. Z., Hugenholtz, P., Larsen, N., Rojas, M., Brodie, E. L., Keller, K., et al. (2006). Greengenes, a chimera-checked 16S rRNA gene database and workbench compatible with ARB. Appl. Environ. Microbiol. 72, 5069-5072. doi: 10.1128/AEM.03006-05

Grace, R. (2007). Oil: an Overview of the Petroleum Industry. Houston, TX: Gulf Publishing Co.

Gray, G. R., Darley, H. C. H., and Rogers, W. F. (1980). Composition and Properties of Oil Well Drilling Fluids. Houston, TX: Gulf Publishing Co.

Green, M. S., Flanegan, K. C., and Gilcrease, P. C. (2008). Characterization of a methanogenic consortium enriched from a coalbed methane well in the Powder River Basin, USA. Int. J. Coal Geol. 76, 34-45. doi: 10.1016/j.coal.2008.05.001

Greene, A. C., Patel, B. K. C., and Yacob, S. (2009). Geoalkalibacter subterraneus sp nov., an anaerobic $\mathrm{Fe}(\mathrm{III})$ - and $\mathrm{Mn}$ (IV)-reducing bacterium from a petroleum reservoir, and emended descriptions of the family Desulfuromonadaceae and the genus Geoalkalibacter. Int. J. Syst. Evol. Microbiol. 59, 781-785. doi: 10.1099/ijs.0.001537-0

Harris, S. H., Smith, R. L., and Barker, C. E. (2008). Microbial and chemical factors influencing methane production in laboratory incubations of low-rank subsurface coals. Int. J. Coal Geol. 76, 46-51. doi: 10.1016/j.coal.2008.05.019

Huang, R. (2008). Shale-Derived Dissolved Organic Matter as a Substrate for Subsurface Methanogenetic Communities in the Antrim Shale Michigan Basin, USA. Master thesis. Department of Geosciences, University of Massachusetts Amherst.

Kerr, R. A. (2010). Natural gas from shale bursts onto the scene. Science 328, 1624-1626. doi: 10.1126/science.328.5986.1624

Kim, H. M., Hwang, C. Y., and Cho, B. C. (2010). Arcobacter marinus sp nov. Int. J. Syst. Evol. Microbiol. 60, 531-536. doi: 10.1099/ijs.0.007740-0

Kirk, M. F., Martini, A. M., Breecker, D. O., Colman, D. R., Takacs-Vesbach, C., and Petsch, S. T. (2012). Impact of commercial natural gas production on geochemistry and microbiology in shal-gas reservoir. Chem. Geol. 332-333, 15-25. doi: 10.1016/j.chemgeo.2012.08.032

Klindworth, A., Pruesse, E., Schweer, T., Peplies, J., Quast, C., Horn, M., et al. (2013). Evaluation of general 16S ribosomal RNA gene PCR primers for classical and next-generation sequencing-based diversity studies. Nucleic Acids Res. 41, el. doi: $10.1093 /$ nar/gks808

Knittel, K., and Boetius, A. (2009). Anaerobic oxidation of methane: progress with an unknown process. Annu. Rev. Microbiol. 63, 311-334. doi: 10.1146/annurev.micro.61.080706.093130

Magot, M., Ollivier, B., and Patel, B. K. C. (2000). Microbiology of petroleum reservoirs. Antonie Van Leeuwenhoek 77, 103-116. doi: 10.1023/A:1002434330514

Martini, A. M., Budai, J. M., Walter, L. M., and Schoell, M. (1996). Microbial generation of economic accumulations of methane within a shallow organic-rich shale. Nature 383, 155-158. doi: 10.1038/383155a0

Martini, A. M., Nüsslein, K., and Petsch, S. T. (2004). Enhancing Microbial Gas from Unconventional Reservoirs: Geochemical and Microbiological Characterization of Methane-Rich Fractured Black Shales. Final Report: RPSEA-0024-04, GRI05/0023. Gas Technology Institute, Des Plaines, IL.

Martini, A. M., Walter, L. M., Budai, J. M., Ku, T. C. W., Kaiser, C. J., and Schoell, M. (1998). Genetic and temporal relations between formation waters and biogenic methane: Upper Devonian Antrim Shale, Michigan Basin, USA. Geochim. Cosmochim. Acta 62, 1699-1720. doi: 10.1016/S0016-7037(98)00090-8

Martini, A. M., Walter, L. M., Ku, T. C. W., Budai, J. M., McIntosh, J. C., and Schoell, M. (2003). Microbial production and modification of gases in sedimentary basins: a geochemical case study from a Devonian shale gas play, Michigan basin. Am. Assoc. Pet. Geol. Bull. 87, 1355-1375. doi: 10.1306/031903200184

Martini, A. M., Walter, L. M., and McIntosh, J. C. (2008). Identification of microbial and thermogenic gas components from Upper Devonian black shale cores, Illinois and Michigan basins. Am. Assoc. Pet. Geol. Bull. 92, 327-339. doi: 10.1306/10180706037

McIntosh, J. C., Walter, L. M., and Martini, A. M. (2002). Pleistocene recharge to midcontinent basins: effects on salinity structure and microbial gas 
generation. Geochim. Cosmochim. Acta 66, 1681-1700. doi: 10.1016/S00167037(01)00885-7

Milkov, A. V. (2011). Worldwide distribution and significance of secondary microbial methane formed during petroleum biodegradation in conventional reservoirs. Org. Geochem. 42, 184-207. doi: 10.1016/j.orggeochem.2010.12.003

Mochimaru, H., Tamaki, H., Hanada, S., Imachi, H., Nakamura, K., Sakata, S., et al. (2009). Methanolobus profundi sp nov., a methylotrophic methanogen isolated from deep subsurface sediments in a natural gas field. Int. J. Syst. Evol. Microbiol. 59, 714-718. doi: 10.1099/ijs.0.001677-0

Mouné, S., Eatock, C., Matheron, R., Willison, J. C., Hirschler, A., Herbert, R., et al. (2000). Orenia salinaria sp. nov., a fermentative bacterium isolated from anaerobic sediments of Mediterranean salterns. Int. J. Syst. Evol. Microbiol. 50, 721-729. doi: 10.1099/00207713-50-2-721

Muyzer, G., De Waal, E., and Uitterlinden, A. (1993). Profiling of complex microbialpopulations by denaturing gradient gelelectrophoresis analysis of polymerase chain reaction-amplified genes coding for $16 \mathrm{~s}$ rRNA. Appl. Environ. Microbiol. 59, 695-700.

Nakagawa, Y., and Yamasato, K. (1996). Emendation of the genus Cytophaga and transfer of Cytophaga agarovorans and Cytophaga salmonicolor to Marinilabilia gen nov: phylogenetic analysis of the Flavobacterium-Cytophaga complex. Int. J. Syst. Bacteriol. 46, 599-603. doi: 10.1099/00207713-46-2-599

Ollivier, B., and Cayol, J. L. (2005). "Fermentative, iron-reducing and nitratereducing microorganisms," in Petroleum Microbiology, eds B. Ollivier and M. Magot (Washington, DC: ASM press), 71-88.

Ollivier, B., Fardeau, M. L., Cayol, J. L., Magot, M., Patel, B. K. C., Prensier, G., et al. (1998). Methanocalculus halotolerans gen. nov., sp. nov., isolated from an oil-producing well. Int. J. Syst. Bacteriol. 48, 821-828. doi: 10.1099/0020771348-3-821

Orem, W. H., Voytek, M. A., Jones, E. J., Lerch, H. E., Bates, A. L., Corum, M. D., et al. (2010). Organic intermediates in the anaerobic biodegradation of coal to methane under laboratory conditions. Org. Geochem. 41, 997-1000. doi: 10.1016/j.orggeochem.2010.03.005

Oren, A. (1990). Formation and breakdown of glycine betaine and trimethylamine in hypersaline environments. Antonie Van Leeuwenhoek 58, 291-298. doi: 10.1007/BF00399342

Oren, A. (1999). Bioenergetic aspects of halophilism. Microbiol. Mol. Biol. Rev. 63, 334.

Oren, A. (2001). The bioenergetic basis for the decrease in metabolic diversity at increasing salt concentrations: implications for the functioning of salt lake ecosystems. Hydrobiologia 466, 61-72. doi: 10.1023/A:1014557116838

Øvreas, L., Forney, L., Daae, F., and Torsvik, V. (1997). Distribution of bacterioplankton in meromictic lake Saelenvannet, as determined by denaturing gradient gel electrophoresis of PCR-amplified gene fragments coding for $16 \mathrm{~S}$ rRNA. Appl. Environ. Microbiol. 63, 3367-3373.

Perreault, N. N., Andersen, D. T., Pollard, W. H., Greer, C. W., and Whyte, L. G. (2007). Characterization of the prokaryotic diversity in cold saline perennial springs of the Canadian high Arctic. Appl. Environ. Microbiol. 73, 1532-1543. doi: 10.1128/AEM.01729-06

Prince, R. C. (2005). “The microbiology of marine oil spill bioremediation," in Petroleum Microbiology, eds B. Ollivier and M. Magot (Washington, DC: ASM press), 317-336.

Qatibi, A. I., Cayol, J. L., and Garcia, J. L. (1991). Glycerol and propanediols degradation by Desulfovibrio-Alcoholovorans in pure culture in the presence of sulfate, or in syntrophic association with Methanospirillum-Hungatei. FEMS Microbiol. Ecol. 85, 233-240. doi: 10.1111/j.1574-6941.1991.tb01728.x

Rainey, F. A., Zhilina, T. N., Boulygina, E. S., Stackebrandt, E., Tourova, T. P., and Zavarzin, G. A. (1995). The taxonomic status of the fermentative halophilic anaerobic-bacteria - description of Haloanaerobiales ordnov, Halobacteroidaceae fam-nov, Orenia gen-nov and further taxonomic rearrangements at the genus and species level. Anaerobe 1, 185-199. doi: 10.1006/anae.1995.1018

Ravot, G., Magot, M., Ollivier, B., Patel, B. K. C., Ageron, E., Grimont, P. A. D., et al. (1997). Haloanaerobium congolense sp nov, an anaerobic, moderately halophilic, thiosulfate- and sulfur-reducing bacterium from an African oil field. FEMS Microbiol. Lett. 147, 81-88. doi: 10.1111/j.1574-6968.1997.tb10224.x

Rice, D. D. (1992). "Controls, habitat, resource potential of ancient bacterial gas," in Bacterial Gas, ed R. Vitaly (Paris: Editions Technip), 91-118.

Sakai, S., Imachi, H., Sekiguchi, Y., Ohashi, A., Harada, H., and Kamagata, Y. (2007). Isolation of key methanogens for global methane emission from rice paddy fields: a novel isolate affiliated with the clone cluster Rice Cluster, I. Appl. Environ. Microbiol. 73, 4326-4331. doi: 10.1128/AEM.03008-06

Schink, B. (2006). Microbially driven redox reactions in anoxic environments: Pathways, energetics, and biochemical consequences. Eng. Life Sci. 6, 228-233. doi: 10.1002/elsc.200620130

Shumkov, S., Terekhova, S., and Laurinavichius, K. (1999). Effect of enclosing rocks and aeration on methanogenesis from coals. Appl. Microbiol. Biotechnol. 52, 99-103. doi: 10.1007/s002530051494

Shurr, G. W., and Ridgley, J. L. (2002). Unconventional shallow biogenic gas systems. Am. Assoc. Pet. Geol. Bull. 86, 1939-1969. doi: 10.1306/61EEDDC8173E-11D7-8645000102C1865D

Simankova, M. V., Chernych, N. A., Osipov, G. A., and Zavarzin, G. A. (1993). Halocella Cellulolytica gen-nov, sp-nov, a new obligately anaerobic, halophilic, cellulolytic bacterium. Syst. Appl. Microbiol. 16, 385-389. doi: 10.1016/S07232020(11)80270-5

Strąpoć, D., Picardal, F. W., Turich, C., Schaperdoth, I., Macalady, J. L., Lipp, J. S., et al. (2008). Methane-producing microbial community in a coal bed of the Illinois basin. Appl. Environ. Microbiol. 74, 3918-3918. doi: 10.1128/AEM.00856-08

Strapoć, D., Mastalerz, M., Dawson, K., Macalady, J., Callaghan, A. V., Wawrik, B., et al. (2011). Biogeochemistry of Microbial Coal-Bed Methane. Annu. Rev. Earth Planet. Sci. 39, 617-656. doi: 10.1146/annurev-earth-040610-133343

Struchtemeyer, C. G., Davis, J. P., and Elshahed, M. S. (2011). Influence of drilling mud formulation process on the bacterial communities in thermogenic natural wells of the Barnett Shale. Appl. Environ. Microbiol. 77, 4744-4753. doi: 10.1128/AEM.00233-11

Struchtemeyer, C. G., and Elshahed, M. S. (2012). Bacterial communities associated with hydraulic fracturing fluids in thermogenic natural gas wells in North Central Texas, USA. FEMS Microbiol. Ecol. 81, 13-25. doi: 10.1111/j.15746941.2011.01196.x

Tarasov, A. L., Borzenkov, I. A., and Belyayev, S. S. (2011). Investigation of the trophic relations between anaerobic microorganisms from an underground gas repository during methanol utilization. Microbiology 80, 180-187. doi: $10.1134 /$ S0026261711020159

Ünal, B., Perry, V. R., Sheth, M., Gomez-Alvarez, V., Chin, K.-J., and Nüsslein, K. (2012). Trace elements affect methanogenic activity and diversity in enrichments from subsurface coal bed produced water. Front. Microbiol. 3:175. doi: $10.3389 /$ fmicb. 2012.00175

Veil, J. (2010). Water Management Technologies used by Marcellus Shale Gas Producers, ANL/EVS/R-10/3, Environmental Environment Devision, Argonne National Laboratory for the U.S. Department of Energy, Office of Fossile Energy, National Energy Technology Laboratory. Chicago.

Waldron, P. J., Petsch, S. T., Martini, A. M., and Nüsslein, K. (2007). Salinity constraints on subsurface archaeal diversity and methanogenesis in sedimentary rock rich in organic matter. Appl. Environ. Microbiol. 73, 4171-4179. doi: 10.1128/AEM.02810-06

Walter, L. M., Budai, J. M., Martini, A. M., and Ku, T. C. W. (1997). Hydrogeochemistry of the Antrim Shale in the Michigan Basin. Des Plaines: Gas Research Institute, GRI-95/0251.

Wang, Y., and Qian, P. Y. (2009). Conservative fragments in bacterial 16S rRNA genes and primer design for $16 \mathrm{~S}$ ribosomal DNA amplicons in metagenomic studies. PLOS ONE 4:e7401. doi: 10.1371/journal.pone. 0007401

Whitman, W. B., Bowen, T. L., and Boone, D. R. (2006). "The methanogenic bacteria," in The Prokaryotes, Vol. 3, eds M. Dworkin, S. Falkow, E. Rosenberg, K.-H. Schleifer, and E. Stackebrandt (New York, NY: Springer), 165-207. doi: 10.1007/0-387-30743-5_9

Wildgruber, G., Thomm, M., Konig, H., Ober, K., Ricchiuto, T., and Stetter, K. O. (1982). Methanoplanus-Limicola, a plate-shaped methanogen representing a novel family, the Methanoplanaceae. Arch. Microbiol. 132, 31-36. doi: 10.1007/BF00690813

Wilharm, T., Zhilina, T. N., and Hummel, P. (1991). DNA-DNA hybridization of methylotrophic halophilic methanogenic bacteria and transfer of Methanococcus-Halophilus vp to the genus Methanohalophilus as Methanohalophilus-Halophilus comb-nov. Int. J. Syst. Bacteriol. 41, 558-562. doi: 10.1099/00207713-41-4-558

Wilhelm, E., Battino, R., and Wilcock, R. (1977). Low-pressure solubility of gases in liquid water. Chem. Rev. 77, 219-262. doi: 10.1021/cr603 $06 \mathrm{a} 003$ 
Wuchter, C., Schouten, S., Coolen, M. J. L., and Sinninghe Damsté, J. S. (2004). Temperature-dependent variation in the distribution of tetraether membrane lipids of marine Crenarchaeota: implications for TEX 86 paleothermometry. Paleoceanography 19, PA4028. doi: 10.1029/2004PA001041

Conflict of Interest Statement: The authors declare that the research was conducted in the absence of any commercial or financial relationships that could be construed as a potential conflict of interest.

Received: 14 August 2013; paper pending published: 29 September 2013; accepted: 18 November 2013; published online: 06 December 2013.
Citation: Wuchter C, Banning E, Mincer TJ, Drenzek NJ and Coolen MJL (2013) Microbial diversity and methanogenic activity of Antrim Shale formation waters from recently fractured wells. Front. Microbiol. 4:367. doi: 10.3389/fmicb.2013.00367

This article was submitted to Microbiotechnology, Ecotoxicology and Bioremediation, a section of the journal Frontiers in Microbiology.

Copyright (C) 2013 Wuchter, Banning, Mincer, Drenzek and Coolen. This is an openaccess article distributed under the terms of the Creative Commons Attribution License (CC BY). The use, distribution or reproduction in other forums is permitted, provided the original author(s) or licensor are credited and that the original publication in this journal is cited, in accordance with accepted academic practice. No use, distribution or reproduction is permitted which does not comply with these terms. 